\title{
Avaliação do comportamento sexual em touros Nelore: comparação entre os testes da libido em curral e do comportamento sexual a campo
}

\section{Cleber Barbosa de Oliveira ${ }^{1}$, José Domingos Guimarães ${ }^{2}$, Eduardo Paulino da Costa ${ }^{2}$, Jeanne Broch Siqueira ${ }^{3}$, Ciro Alexandre Alves Torres ${ }^{4}$, Giovanni Ribeiro de Carvalho ${ }^{4}$, Simone Eliza Facioni Guimarães ${ }^{4}$}

\footnotetext{
1 Veterinário autônomo.

2 Departamento de Veterinária - UFV.

${ }^{3}$ Doutoranda FMVZ/UNESP - Botucatu.

${ }^{4}$ Departamento de Zootecnia - UFV.
}

RESUMO - Objetivou-se determinar a eficiência do teste da libido realizado em curral em comparação ao teste realizado a campo e relacioná-los à taxa de gestação em estação de monta de 120 dias. Treze touros aptos à reprodução foram submetidos ao teste da libido em curral por 3 horas. Desses touros, nove foram submetidos à avaliação a campo na proporção touro:vaca de 1:33. A cada 21 dias, foi diagnosticada a gestação por meio de avaliações ultra-sonográficas. No teste em curral, observou-se que, quanto maior o tempo, maiores foram os escores de classificação e que nenhum touro efetuou serviço completo nos 10 minutos iniciais do teste. Com um touro classificado como muito bom obteve-se 84,80\% de prenhez, porém touros questionáveis proporcionaram taxas de prenhez de 86,67 e 96,55\% ao final da estação. As correlações entre características físicas e morfológicas do sêmen mantiveram-se próximas de zero ou foram nulas. Os principais sinais fisiológicos do comportamento sexual foram o ato de cheirar ou lamber o corpo da fêmea, cheirar ou lamber a vulva, seguidos ou não por reflexo de Flehmen. Em animais da raça Nelore, o tempo de 30 minutos de observação mostrou-se mais eficiente para a realização do teste da libido em curral. O teste da libido realizado a campo no período diurno não foi eficaz em predizer a libido de todos os animais estudados, em decorrência, provavelmente, do comportamento sexual noturno de alguns reprodutores.

Palavras-chave: comportamento sexual, libido, teste da libido, zebuínos

\section{Evaluation of the sexual behavior of Nelore bulls: a comparison between the libido test in corral and the sexual behavior at field}

\begin{abstract}
The objectives of this study were to determine the efficiency of the libido test in corral compared to the test performed at field and to relate them to the gestation rate observed in a breeding season of 120 days. Thirteen Nelore bulls able to reproduce were submitted to the libido test in corral for 3 hours and evaluated by scores every five minutes. Nine of them were submitted to evaluation at field using a bull:cow proportion equal to 1:33. The gestation was diagnosed every 21 days through ultrasonographic evaluation. During the test in corral, the classification scores increased as the testing time increased, but no bull accomplished complete service in the first 10 minutes of the test. A very good bull obtained $84.80 \%$ for pregnancy rate, but other questionable bulls obtained 86.67 and $96.55 \%$ at the end of the breeding season. Correlations estimates among physical and morphologic characteristics of the semen were close to zero or null. The main physiologic indicators of the bull sexual behavior were: smelling or licking the female body, smelling or licking the vulva, followed or not by the Flehmen reflex. The results suggested 30 minutes of observation as the most efficient time to evaluate the libido test in corral. The libido test at field during daytime was not effective probably because of the sexual behavior of some bulls at night.
\end{abstract}

Key Words: libido, libido test, sexual behavior, zebu

\section{Introdução}

A pecuária brasileira possui um rebanho de aproximadamente 185 milhões de bovinos (IBGE, 2004), sendo $81 \%$ animais de corte, na maioria azebuados com predominância da raça Nelore, o que pode ser atribuído à precocidade e à alta prolificidade da raça e também à adaptabilidade a diferentes condições de criação e manejo no Brasil tropical (Vale Filho, 1997).

Considerando que 55\% do rebanho brasileiro é composto de fêmeas em idade reprodutiva (Anualpec, 2002) e que apenas $7 \%$ delas são inseminadas (Asbia, 2003), pode-se afirmar que $93 \%$ das fêmeas são cobertas em manejo de monta natural. Dessa forma, o touro apresenta bastante 
relevância no processo reprodutivo, principalmente se considerar que $90 \%$ dos touros usados na pecuária de corte não são animais selecionados e testados quanto à libido, à capacidade de serviço, ao exame andrológico e ao ganho de peso (Yassu, 1996). Assim, não se pode admitir que a relação touro/vaca utilizada na maioria dos rebanhos, atualmente $1: 25$ ou 1:30, permaneça inalterada, ocasionando subutilização dos machos (Crudeli, 1990; Costa \& Silva, 1994; Santos, 2000) e acarretando elevado custo ao bezerro produzido (Galvani, 1998).

Identificando touros de alta libido no rebanho, é possível reduzir a duração da estação de monta e facilitar o manejo da propriedade concentrando o nascimento em apenas dois meses. Dessa forma, é possível obter lotes de bezerros homogêneos e maior facilidade na comercialização destes animais, ressaltando-se ainda que a alteração na proporção tradicional touro:vaca de $1: 25$ para $1: 40$ ou $1: 60$ acarreta reduções de 10,4 e $16,2 \%$, respectivamente, no custo de cada bezerro desmamado (Fonseca, 1995). A economia obtida com a utilização da proporção 1:90, quando comparada a 1:30, acarretou redução de $20,97 \%$ no custo do bezerro (Galvani, 1998).

Atualmente, uma metodologia adotada para avaliar a libido de touros zebuínos é a tabela elaborada por Pineda et al. (1997a) e preconizada pelo Colégio Brasileiro de Reprodução Animal (CBRA, 1998). O teste é realizado no curral, com período de observação de 10 minutos, atribuindo-se escores de 0 (sem interesse sexual) a 10 (duas ou mais montas com serviço completo).

$\mathrm{Na}$ raça Nelore, os testes da libido caracterizam bem os animais de alta capacidade de monta, mas muitas vezes o comportamento sexual em regime de monta natural não é adequado a touros de baixa libido. A razão provável é o comportamento dos zebuínos no curral, indicando que é preciso ajustar o teste para a raça Nelore, visando estabelecer sua relação com a capacidade de monta a campo (Yassu, 1996). Santos (2000) afirmou que os efeitos de dominância e do estresse atribuídos ao teste realizado no curral podem comprometer os resultados finais. Entretanto, Fonseca et al. (1996) e Pineda et al. (2000) avaliaram a libido de touros Nelore em curral e verificaram que aqueles de alta libido proporcionaram taxa de prenhez superior a $90 \%$ quando comparados aos de baixa e média libido em estação de monta de 63 dias, o que reforça a importância da realização do teste de libido. Pineda (1996) destacou haver diferença entre as taxas de prenhez de animais de alta libido e daqueles de média e baixa libido, embora não tenha observado diferença entre animais de média e baixa libido.

Pineda \& Lemos (1994) e Pineda et al. (2000) relataram que o grande desafio continua sendo a identificação de touros de baixo desempenho sexual em testes de curral. Alguns autores (Chenoweth, 1983; Barbosa, 1987; Fonseca et al., 1996; Galvani, 1998; Santos et al., 2004) observaram que as correlações entre circunferência escrotal, consistência testicular, características morfológicas de sêmen, libido e capacidade de monta são próximas de zero, o que confirma a pressuposição de que o teste da libido deve ser utilizado como avaliação complementar ao exame andrológico (Costa e Silva, 1994).

Os objetivos neste trabalho foram avaliar o comportamento sexual de touros Nelore (Bos taurus indicus) durante testes da libido em curral e a campo, analisar a relação entre as características físicas e morfológicas do sêmen, a biometria testicular e a libido e determinar a eficiência dos métodos de avaliação da libido quanto à taxa de prenhez.

\section{Material e Métodos}

$\mathrm{O}$ experimento foi realizado em uma propriedade no município de Brotas/SP no período de outubro de 1999 a março de 2000. Treze touros da raça Nelore, linhagem Lemgruber, de 35 a 46 meses, classificados como aptos à reprodução em exame andrológico, foram submetidos ao teste da libido em curral. Desses touros, nove foram submetidos à avaliação do comportamento sexual a campo.

Os reprodutores encontravam-se em repouso sexual e, após contenção individual, foram submetidos à biometria testicular com auxílio de fita métrica para obtenção do perímetro escrotal.

Realizou-se uma coleta de sêmen por animal utilizando-se o método de eletroejaculação. Imediatamente após as coletas, as características físicas do ejaculado foram analisadas conforme metodologia descrita por Fonseca et al. (1991), para determinação do movimento em massa dos espermatozóides (turbilhonamento), em uma escala de 0 a 5. Para análise, o sêmen $(10 \mu \mathrm{L})$ foi depositado sobre uma lâmina previamente aquecida a $37^{\circ} \mathrm{C}$ e avaliado com auxílio de microscopia convencional e aumento de 200x. Posteriormente, com outra alíquota de sêmen $(10 \mu \mathrm{L})$ entre lâmina e lamínula, previamente aquecidas a $37^{\circ} \mathrm{C}$, foram avaliados a motilidade espermática progressiva retilínea $(0-100 \%)$ e o vigor espermático $(0$ - 5$)$ com aumento de 200 a 400x em microscópio de contraste de fase (Olympus, modelo 400B). Em seguida, uma alíquota de sêmen $(20 \mu \mathrm{L})$ foi acondicionada em $1 \mathrm{~mL}$ de solução formol salina tamponada para posterior contagem dos espermatozóides em câmara de Neubauer para determinação da concentração por $\mathrm{mL}$ e no ejaculado total.

Para o estudo morfológico dos espermatozóides, uma alíquota de sêmen (20 a 50 microlitros) de cada ejaculado foi 
acondicionada em $1 \mathrm{~mL}$ de solução formol salina tamponada (quantidade necessária para turvar a solução) e analisada segundo critérios descritos por Blom $(1973 ; 1983)$. As análises foram feitas em preparações úmidas sob imersão. Foram avaliadas 400 células por ejaculado, com auxílio de microscópio de contraste de fase com aumento de 1000x, registrando-se os valores percentuais de patologias de acrossoma, cabeça e cauda, posteriormente classificados em defeitos espermáticos maiores, menores e totais.

Para o teste da libido em curral, foram utilizadas quatro vacas em estro induzido (Sincrocio ${ }^{\circledR}$. Laboratórios Ouro Fino) com $\mathrm{PGF}_{2 \alpha}$ ou natural: duas foram contidas por laços em volta do chifre e amarradas na cerca do curral e duas foram soltas em um único piquete do curral. Os touros foram testados individualmente por período de 3 horas e, de acordo com seu desempenho (analisado a cada 5 minutos), foram classificados segundo um escore de libido de acordo com a Tabela de Classificação da Libido de Touros Zebuínos, segundo o Colégio Brasileiro de Reprodução Animal (CBRA, 1998) (Tabela 1).

Considerando os escores da Tabela 1, os touros foram classificados da seguinte forma: 0 a 3 - questionável; 4 a 6 - bom; 7 a 8 - muito bom; 9 a 10 - excelente ou superior.

Os touros testados a campo foram distribuídos em piquetes com proporção touro:vaca (1:33) pré-estabelecida como manejo de rotina na propriedade, de modo que, a partir do início do estro natural de uma fêmea, foi observado, durante 13 horas (6 às 19h), o comportamento individual de cada touro, rastreado por um observador (com binóculo) a cavalo, a distância de 50 a 100 m, de modo que não interferisse no comportamento dos animais. Os sinais fisiológicos de comportamento sexual dos touros foram agrupados de hora em hora e registrados ao final das 13 horas para avaliação de seu comportamento em relação ao teste realizado em curral.

A estação de monta (120 dias) foi dividida, para efeito de estudo, em períodos cíclicos de 21 dias, de modo que os touros integraram lotes relativamente homogêneos, de acordo com as características raciais e o peso das novilhas com aproximadamente 2 anos de idade, sendo testados individualmente na proporção touro:novilha de 1:33. Após 21 dias de estação de monta, os touros foram separados das fêmeas por um período de dez dias, quando foram reintroduzidos ao grupo. O mesmo procedimento foi repetido após o final do segundo ciclo (21 dias após a reintrodução dos touros) e ao final do terceiro ciclo (21 dias após a reintrodução dos touros). Posteriormente, foram reintroduzidos até o final da estação de monta. O diagnóstico de gestação foi realizado por avaliação ultra-sonográfica
Tabela 1 - Classificação da libido de touros zebuínos Table 1 - Classification of the libido of zebu bulls

\begin{tabular}{|c|c|}
\hline $\begin{array}{l}\text { Pontuação } \\
\text { Punctuation }\end{array}$ & $\begin{array}{l}\text { Atitude } \\
\text { Attitude }\end{array}$ \\
\hline 0 & $\begin{array}{l}\text { Sem interesse sexual } \\
\text { No sexual interest }\end{array}$ \\
\hline 1 & $\begin{array}{l}\text { Identificação da fêmea em cio } \\
\text { (olfação com reflexo de Flehmen) } \\
\text { Identification of female on heat } \\
\text { (smelling and Flehmen reflex) }\end{array}$ \\
\hline 2 & $\begin{array}{l}\text { Olfação e perseguição insistente } \\
\text { Smelling and continuous accompaniment }\end{array}$ \\
\hline 3 & $\begin{array}{l}\text { Tentativa de monta sem salto, } \\
\text { com mugido, deslocamento e masturbação } \\
\text { Mount attempt without jumping, } \\
\text { mooing, moving and masturbation }\end{array}$ \\
\hline 4 & $\begin{array}{l}\text { Tentativa de monta sem salto, com pênis exposto } \\
\text { Mount attempt without jumping, with penis exhibition }\end{array}$ \\
\hline 5 & $\begin{array}{l}\text { Tentativa de monta com salto e pênis exposto } \\
\text { Mount attempt by jumping and penis exhibition }\end{array}$ \\
\hline 6 & $\begin{array}{l}\text { Duas ou mais tentativas de monta } \\
\text { com salto, sem pênis exposto } \\
\text { Two or more mount attempts by } \\
\text { jumping without penis exhibition }\end{array}$ \\
\hline 7 & $\begin{array}{l}\text { Tentativas de montas com salto e } \\
\text { pênis exposto, sem introdução } \\
\text { Mount attempts by jumping with } \\
\text { penis exhibition, but no penetration }\end{array}$ \\
\hline 8 & $\begin{array}{l}\text { Duas ou mais tentativas de monta } \\
\text { com salto e pênis exposto, sem introdução } \\
\text { Two or more mount attempts by jumping } \\
\text { and penis exhibition, but no penetration }\end{array}$ \\
\hline 9 & $\begin{array}{l}\text { Monta com serviço complete } \\
\text { Mount with complete service }\end{array}$ \\
\hline 10 & $\begin{array}{l}\text { Duas ou mais montas com serviço completo } \\
\text { Two or more mounts with complete service }\end{array}$ \\
\hline
\end{tabular}

Pineda et al. (1997a).

(Ultrassom Pie Medical - VET 200 e transdutor 5,0/7,5 MHz), nos dias 43, 54, 75 após início da estação e 22 dias após o final da estação. O período de gestação mais precoce detectado nas avaliações ultrasonográficas foi de 22 dias, possibilitando obter a taxa de prenhez nos três ciclos reprodutivos das fêmeas. Posteriormente, o diagnóstico final da estação de monta foi realizado por meio de palpação transretal no $155^{\circ}$ dia após o início da estação.

A taxa de gestação foi determinada durante cada ciclo de 21 dias, considerando o número de fêmeas gestantes em relação ao total de fêmeas que constituíram o grupo experimental (292 fêmeas).

Os dados de todas as variáveis foram submetidos a análises estatísticas descritivas, à correlação simples de Pearson e às análises de variância e regressão linear simples e multivariada. Os dados das características qualitativas (taxa de gestação) foram submetidos à avaliação dos dados 
em tabelas de contingência e à posterior análise por quiquadrado, com grau de liberdade igual a $1 \mathrm{e}$ probabilidade de erro de $5 \%$.

\section{Resultados e Discussão}

As frequiências médias dos eventos relacionados ao comportamento sexual dos touros durante os testes da libido em curral estão sumarizados na Tabela 2 . Na primeira hora de teste, houve maior número dos atos de cheirar e/ou lamber o corpo (CC), cheirar e/ou lamber a vulva (CV) e reflexo de Flehmen (RF), que diminuiu nas duas horas posteriores estabilizando-se em um patamar, sugerindo que, inicialmente, o touro identifica o status reprodutivo da fêmea por meio destes três eventos. Posteriormente, testam sua receptividade, fato comprovado pelo maior número de reflexo de monta (RM) nas segundas e terceiras horas.

Ressalta-se que nenhum dos animais realizou serviço completo durante o tempo de teste descrito na Tabela de Classificação de Libido de Touros Zebuínos (10 minutos), preconizada pelo CBRA (1998); o animal que realizou serviço completo em menor tempo o fez com 17 minutos.

As frequiências médias de eventos relacionados ao comportamento sexual a campo foram variadas entre os touros e estão sumariadas na Tabela 3 . O comportamento inicial de reconhecimento da fêmea em estro está relacionado aos atos de cheirar/lamber o corpo (CC) ou a vulva (CV), seguidos de RF, conforme descrito por Santos et al. (1999). Outro recurso para testar a receptividade da fêmea foi o reflexo de monta (RM), seguido ou não da exposição de pênis (EP). Além disso, poucas tentativas de monta (TM) e de monta abortada (MA) podem ser uma estratégia para redução do gasto energético, conforme descrito por Costa e Silva et al. (1999), pois o reflexo de monta auxilia na identificação das fêmeas em estro. Observou-se também que os touros realizaram poucos serviços completos (SC) durante o dia, indicando possivelmente, comportamento noturno de alguns reprodutores, visto que quatro deles $(1,2,4$ e 7$) \quad(44,44 \%)$ não efetuaram nenhum serviço completo durante as 13 horas de observação.

Verificou-se também que das 6 às $7 \mathrm{~h}$, os comportamentos mais freqüentes foram CV e RF. No período das 7 às $8 \mathrm{~h}$, ocorreram mais RMe CV e, no horário de 8 às $9 \mathrm{~h}$, continuou havendo mais RM seguido por EP. Na hora seguinte, o sinal fisiológico de maior frequiência foi o RM (Tabela 3). Houve muita semelhança no comportamento inicial dos touros, observando-se, inicialmente, maior número de eventos relacionados ao reconhecimento das fêmeas em estro $(\mathrm{CV}$, $\mathrm{RF}$ ), seguidos de eventos relacionados ao teste da receptividade da fêmea em estro (RM, EP), o que permite concluir que também a campo o reconhecimento das fêmeas em estro ocorre nas primeiras horas do dia.

Entre 10 e $11 \mathrm{~h}$, houve menor manifestação de sinais. No intervalo posterior, no entanto, ocorreram as maiores médias de $\mathrm{CC}, \mathrm{CV}, \mathrm{RFe} \mathrm{AF}$, com aumento também de RMem comparação à hora anterior. No intervalo de 12 às $13 \mathrm{~h}$, observou-se mesmo número de RM, porém com redução nos outros eventos. Entre 13 e 14h, verificou-se aumento de RM seguido também de aumento de EP, de modo que, entre 14 e 15h ocorreu o maior índice de RM do dia (Tabela 3). Nas horas mais quentes do dia (das 11 às 15h), ocorreu maior número de CC, CV, RF, RM, EP, MA, AF e TM em comparação aos períodos menos quentes (das 6 às 11 e das 15 às 19h), quando ocorreu maior número de MSEPe SC, indicando não haver um horário pré-definido do dia para o animal investigar a conduta sexual e a cópula.

Ao final do período de observação (das 18 às 19h), observou-se maior número de RM, EP e CV nos animais a campo, todavia, proporcionalmente, houve maior índice de RM, EP e aumento em números absolutos no número de $\mathrm{CV}$ e de animais submetidos ao teste de curral (Tabela 3).

Os valores obtidos para motilidade espermática progressiva e vigor foram $73,3 \pm 7,7$ e $3,8 \pm 0,6$, respectivamente (Tabela 4), o que está de acordo com os padrões preconi-

Tabela 2 - Freqüências médias dos eventos relacionados ao comportamento sexual de touros Nelore durante os testes da libido em curral durante 3 horas de observação

Table 2 - $\quad$ Average frequencies of the events related to the sexual behavior of Nelore bulls submitted to the libido test in corral for 3 hours

\begin{tabular}{lccrrrrrrrrrr}
\hline $\begin{array}{l}\text { Tempo }(\mathrm{h}) \\
\text { Time }(h)\end{array}$ & CC & CV & RF & RM & EP & TM & MSEP & MA & PC & AF & SC & FF \\
\hline $0-1$ & 19,00 & 39,56 & 28,78 & 15,22 & 7,56 & 1,67 & 0,00 & 1,22 & 0,33 & 3,00 & 0,44 & 1,11 \\
$1-2$ & 12,67 & 18,67 & 10,00 & 24,67 & 10,00 & 1,11 & 0,00 & 0,78 & 0,44 & 2,11 & 1,44 & 1,11 \\
$2-3$ & 12,00 & 19,10 & 8,22 & 26,11 & 9,33 & 1,67 & 0,11 & 0,78 & 0,67 & 2,22 & 0,89 & 1,44 \\
Total & 43,67 & 77,33 & 47,00 & 66,00 & 26,89 & 4,44 & 0,11 & 2,78 & 1,44 & 7,33 & 2,78 & 3,56 \\
\hline
\end{tabular}

CC - ato de cheirar/lamber o corpo da fêmea; CV - ato de cheirar/lamber a vulva; RF - reflexo de Flehmen; RM - reflexo de monta; EP - exposição de pênis TM - tentativa de monta; MSEP - monta sem exposição de pênis; MA - monta abortada; PC - pressão no cupim; AF - acompanhamento de fêmeas; SC - serviço completo; FF - frente a frente.

CC-smelling and/or licking of body; CV-smelling and/or licking of vulva; RF-Flehmen reflex; RM-mount reflex; EP-penis exhibition; TM-mount attempt; MSEP-mount withoutpenis exhibition; $M A$ - false-mount; $P C$ - pressure in hump; $A F$-accompaniment of females; $S C$ - complete service; $F F$-face to face. 
Tabela 3 - Freqüências médias dos eventos relacionados ao comportamento sexual de touros Nelore durante observação a campo (13 horas)

Table 3 - Average frequencies of the events related to the sexual behavior of Nelore bulls submitted to evaluation at field for 13 hours

\begin{tabular}{|c|c|c|c|c|c|c|c|c|c|c|c|c|}
\hline $\begin{array}{l}\text { Horas }{ }^{1} \\
\text { Hours }\end{array}$ & $\mathrm{CC}$ & $\mathrm{CV}$ & $\mathrm{RF}$ & $\mathrm{RM}$ & EP & T M & MSEP & MA & $\mathrm{PC}$ & $\mathrm{AF}$ & SC & $\mathrm{FF}$ \\
\hline $\begin{array}{l}6-7 \\
+\end{array}$ & $\begin{array}{r}1,67 \\
(0-6)\end{array}$ & $\begin{array}{r}3,78 \\
(1-7)\end{array}$ & $\begin{array}{r}2,67 \\
(0-7)\end{array}$ & $\begin{array}{l}1,11 \\
(0-4)\end{array}$ & $\begin{array}{r}0,22 \\
(0-1)\end{array}$ & $\begin{array}{r}0,00 \\
(0)\end{array}$ & $\begin{array}{r}0,00 \\
(0)\end{array}$ & $\begin{array}{r}0,00 \\
(0)\end{array}$ & $\begin{array}{r}0,11 \\
(0-1)\end{array}$ & $\begin{array}{r}1,33 \\
(0-4)\end{array}$ & $\begin{array}{r}0,00 \\
(0)\end{array}$ & $\begin{array}{c}0,22 \\
(0-2)\end{array}$ \\
\hline $\begin{array}{l}7-8 \\
+\end{array}$ & $\begin{array}{r}1,78 \\
(0-4)\end{array}$ & $\begin{array}{r}4,33 \\
(0-12)\end{array}$ & $\begin{array}{r}2,67 \\
(0-9)\end{array}$ & $\begin{array}{r}8,11 \\
(0-34)\end{array}$ & $\begin{array}{r}2,67 \\
(0-20)\end{array}$ & $\begin{array}{r}0,56 \\
(0-5)\end{array}$ & $\begin{array}{r}0,00 \\
(0)\end{array}$ & $\begin{array}{r}0,11 \\
(0-1)\end{array}$ & $\begin{array}{r}0,22 \\
(0-1)\end{array}$ & $\begin{array}{r}2,56 \\
(0-4)\end{array}$ & $\begin{array}{r}0,00 \\
(0)\end{array}$ & $\begin{array}{c}0,56 \\
(0-2)\end{array}$ \\
\hline $\begin{array}{l}8-9 \\
+\end{array}$ & $\begin{array}{l}1,11 \\
(0-4)\end{array}$ & $\begin{array}{r}3,00 \\
(0-10)\end{array}$ & $\begin{array}{r}1,67 \\
(0-8)\end{array}$ & $\begin{array}{r}6,78 \\
(0-19)\end{array}$ & $\begin{array}{r}4,22 \\
\left(\begin{array}{ll}0 & -20\end{array}\right)\end{array}$ & $\begin{array}{r}0,78 \\
(0-5)\end{array}$ & $\begin{array}{r}0,00 \\
(0)\end{array}$ & $\begin{array}{r}0,67 \\
(0-3)\end{array}$ & $\begin{array}{r}0,11 \\
(0-1)\end{array}$ & $\begin{array}{r}1,56 \\
(0-3)\end{array}$ & $\begin{array}{r}0,11 \\
(0-1)\end{array}$ & $\begin{array}{r}0,56 \\
(0-5)\end{array}$ \\
\hline $\begin{array}{l}9-10 \\
+\end{array}$ & $\begin{array}{r}1,33 \\
(0-3)\end{array}$ & $\begin{array}{r}2,56 \\
(1-4)\end{array}$ & $\begin{array}{r}1,00 \\
(0-3)\end{array}$ & $\begin{array}{r}6,00 \\
(0-21)\end{array}$ & $\begin{array}{r}2,56 \\
(0-11)\end{array}$ & $\begin{array}{r}0,56 \\
(0-4)\end{array}$ & $\begin{array}{r}0,00 \\
(0)\end{array}$ & $\begin{array}{r}0,22 \\
(0-2)\end{array}$ & $\begin{array}{c}0,11 \\
(0-1)\end{array}$ & $\begin{array}{r}1,56 \\
(0-4)\end{array}$ & $\begin{array}{r}0,22 \\
(0-1)\end{array}$ & $\begin{array}{r}0,67 \\
(0-3)\end{array}$ \\
\hline $\begin{array}{l}10-11 \\
+\end{array}$ & $\begin{array}{r}1,33 \\
(0-6)\end{array}$ & $\begin{array}{r}2,22 \\
(0-12)\end{array}$ & $\begin{array}{r}1,56 \\
(0-11)\end{array}$ & $\begin{array}{r}2,78 \\
(0-9)\end{array}$ & $\begin{array}{r}0,56 \\
(0-3)\end{array}$ & $\begin{array}{r}0,11 \\
(0-1)\end{array}$ & $\begin{array}{r}0,11 \\
(0-1)\end{array}$ & $\begin{array}{r}0,00 \\
(0)\end{array}$ & $\begin{array}{r}0,00 \\
(0)\end{array}$ & $\begin{array}{r}1,33 \\
(0-7)\end{array}$ & $\begin{array}{r}0,00 \\
(0)\end{array}$ & $\begin{array}{r}0,33 \\
(0-1)\end{array}$ \\
\hline $\begin{array}{l}11-12 \\
+\end{array}$ & $\begin{array}{r}2,33 \\
(0-6)\end{array}$ & $\begin{array}{r}5,22 \\
(0-10)\end{array}$ & $\begin{array}{r}3,00 \\
(0-7)\end{array}$ & $\begin{array}{r}6,00 \\
(0-32)\end{array}$ & $\begin{array}{r}2,11 \\
(0-17)\end{array}$ & $\begin{array}{r}0,44 \\
(0-3)\end{array}$ & $\begin{array}{r}0,00 \\
(0)\end{array}$ & $\begin{array}{r}0,00 \\
(0)\end{array}$ & $\begin{array}{r}0,00 \\
(0)\end{array}$ & $\begin{array}{r}4,00 \\
(1-9)\end{array}$ & $\begin{array}{r}0,00 \\
(0)\end{array}$ & $\begin{array}{r}0,56 \\
(0-2)\end{array}$ \\
\hline $\begin{array}{l}12-13 \\
+\end{array}$ & $\begin{array}{r}0,89 \\
(0-3)\end{array}$ & $\begin{array}{r}2,33 \\
(0-9)\end{array}$ & $\begin{array}{r}1,56 \\
(0-7)\end{array}$ & $\begin{array}{r}6,00 \\
(0-11)\end{array}$ & $\begin{array}{r}4,00 \\
(0-14)\end{array}$ & $\begin{array}{r}0,67 \\
(0-3)\end{array}$ & $\begin{array}{r}0,00 \\
(0)\end{array}$ & $\begin{array}{r}1,00 \\
(0-7)\end{array}$ & $\begin{array}{r}0,00 \\
(0)\end{array}$ & $\begin{array}{r}1,56 \\
(0-8)\end{array}$ & $\begin{array}{r}0,11 \\
(0-1)\end{array}$ & $\begin{array}{r}0,44 \\
(0-2)\end{array}$ \\
\hline $\begin{array}{l}13-14 \\
+\end{array}$ & $\begin{array}{r}1,00 \\
(0-3)\end{array}$ & $\begin{array}{r}2,44 \\
(0-10)\end{array}$ & $\begin{array}{r}1,00 \\
(0-4)\end{array}$ & $\begin{array}{r}8,67 \\
(0-30)\end{array}$ & $\begin{array}{r}5,78 \\
(0-16)\end{array}$ & $\begin{array}{r}1,22 \\
(0-5)\end{array}$ & $\begin{array}{r}0,00 \\
(0)\end{array}$ & $\begin{array}{r}0,33 \\
(0-2)\end{array}$ & $\begin{array}{r}0,11 \\
(0-1)\end{array}$ & $\begin{array}{r}2,11 \\
(0-7)\end{array}$ & $\begin{array}{r}0,11 \\
(0-1)\end{array}$ & $\begin{array}{c}0,33 \\
(0-2)\end{array}$ \\
\hline $\begin{array}{l}14-15 \\
+\end{array}$ & $\begin{array}{r}1,00 \\
(0-3)\end{array}$ & $\begin{array}{r}2,78 \\
(0-8)\end{array}$ & $\begin{array}{r}0,78 \\
(0-2)\end{array}$ & $\begin{array}{r}9,33 \\
(0-27)\end{array}$ & $\begin{array}{r}4,00 \\
(0-19)\end{array}$ & $\begin{array}{r}1,00 \\
(0-3)\end{array}$ & $\begin{array}{r}0,00 \\
(0)\end{array}$ & $\begin{array}{r}0,00 \\
(0)\end{array}$ & $\begin{array}{r}0,00 \\
(0)\end{array}$ & $\begin{array}{r}2,89 \\
(1-7)\end{array}$ & $\begin{array}{r}0,11 \\
(0-1)\end{array}$ & $\begin{array}{c}0,67 \\
(0-2)\end{array}$ \\
\hline $\begin{array}{l}15-16 \\
+\end{array}$ & $\begin{array}{r}1,11 \\
(0-4)\end{array}$ & $\begin{array}{l}1,89 \\
(0-6)\end{array}$ & $\begin{array}{r}0,67 \\
(0-3)\end{array}$ & $\begin{array}{r}7,11 \\
(0-24)\end{array}$ & $\begin{array}{r}3,33 \\
(0-17)\end{array}$ & $\begin{array}{r}0,56 \\
(0-4)\end{array}$ & $\begin{array}{r}0,00 \\
(0)\end{array}$ & $\begin{array}{r}0,11 \\
(0-1)\end{array}$ & $\begin{array}{r}0,11 \\
(0-1)\end{array}$ & $\begin{array}{r}2,33 \\
(0-5)\end{array}$ & $\begin{array}{r}0,33 \\
(0-2)\end{array}$ & $\begin{array}{r}0,67 \\
(0-4)\end{array}$ \\
\hline $\begin{array}{l}16-17 \\
+\end{array}$ & $\begin{array}{r}0,44 \\
(0-3)\end{array}$ & $\begin{array}{r}1,89 \\
(0-4)\end{array}$ & $\begin{array}{r}1,11 \\
(0-3)\end{array}$ & $\begin{array}{r}3,00 \\
(0-11)\end{array}$ & $\begin{array}{r}1,11 \\
(0-9)\end{array}$ & $\begin{array}{r}0,22 \\
(0-2)\end{array}$ & $\begin{array}{r}0,00 \\
(0)\end{array}$ & $\begin{array}{r}0,00 \\
(0)\end{array}$ & $\begin{array}{r}0,00 \\
(0)\end{array}$ & $\begin{array}{r}2,67 \\
(1-5)\end{array}$ & $\begin{array}{r}0,00 \\
(0)\end{array}$ & $\begin{array}{r}0,44 \\
(0-1)\end{array}$ \\
\hline $\begin{array}{l}17-18 \\
+\end{array}$ & $\begin{array}{r}0,11 \\
(0-1)\end{array}$ & $\begin{array}{r}0,89 \\
(0-4)\end{array}$ & $\begin{array}{r}0,56 \\
(0-2)\end{array}$ & $\begin{array}{r}5,78 \\
(0-29)\end{array}$ & $\begin{array}{r}5,00 \\
(0-33)\end{array}$ & $\begin{array}{r}0,67 \\
(0-5)\end{array}$ & $\begin{array}{r}0,00 \\
(0)\end{array}$ & $\begin{array}{r}0,33 \\
(0-1)\end{array}$ & $\begin{array}{r}0,00 \\
(0)\end{array}$ & $\begin{array}{r}1,56 \\
(0-6)\end{array}$ & $\begin{array}{r}0,11 \\
(0-1)\end{array}$ & $\begin{array}{r}0,11 \\
(0-1)\end{array}$ \\
\hline $\begin{array}{l}18-19 \\
+\end{array}$ & $\begin{array}{r}0,00 \\
(0)\end{array}$ & $\begin{array}{r}0,56 \\
(0-3)\end{array}$ & $\begin{array}{r}0,22 \\
(0-2)\end{array}$ & $\begin{array}{r}1,11 \\
(0-7)\end{array}$ & $\begin{array}{r}0,89 \\
(0-7)\end{array}$ & $\begin{array}{r}0,00 \\
(0)\end{array}$ & $\begin{array}{r}0,00 \\
(0)\end{array}$ & $\begin{array}{r}0,00 \\
(0)\end{array}$ & $\begin{array}{r}0,00 \\
(0)\end{array}$ & $\begin{array}{r}0,56 \\
(0-3)\end{array}$ & $\begin{array}{r}0,00 \\
(0)\end{array}$ & $\begin{array}{c}0,11 \\
(0-1)\end{array}$ \\
\hline $\begin{array}{l}\text { Total } \\
+\end{array}$ & $\begin{array}{r}14,11 \\
(0-6)\end{array}$ & $\begin{array}{r}33,89 \\
(0-12)\end{array}$ & $\begin{array}{r}18,44 \\
(0-11)\end{array}$ & $\begin{array}{r}71,78 \\
(0-34)\end{array}$ & $\begin{array}{c}36,44 \\
(0-20)\end{array}$ & $\begin{array}{r}6,78 \\
(0-5)\end{array}$ & $\begin{array}{r}0,11 \\
(0-1)\end{array}$ & $\begin{array}{r}2,78 \\
(0-7)\end{array}$ & $\begin{array}{r}0,78 \\
(0-1)\end{array}$ & $\begin{array}{r}26,00 \\
(0-9)\end{array}$ & $\begin{array}{r}1,11 \\
(0-2)\end{array}$ & $\begin{array}{c}5,67 \\
(0-5)\end{array}$ \\
\hline
\end{tabular}

${ }^{1}$ do dia; + Amplitude dos sinais fisiológicos.

CC - ato de cheirar/lamber o corpo; CV - ato de cheirar/lamber a vulva; RF - reflexo de Flehmen; RM - reflexo de monta; EP - exposição de pênis; TM - tentativa de monta; MSEP - monta sem exposição de pênis; MA - monta abortada; PC - pressão no cupim; AF - acompanhamento de fêmeas; SC - serviço completo; FF - frente a frente.

${ }^{1}$ day time; ${ }^{+}$Range of the physiologic signs.

CC-smelling and/or licking of body; CV-smelling and/or licking of vulva; RF-Flehmen reflex; RM-mount reflex; EP-penis exhibition; TM-mount attempt; MSEP-mount without penis exhibition; $M A$ - false-mount; $P C$ - pressure in hump; $A F$ - accompaniment of females; $S C$-complete service; $F F$ - face to face.

zados pelo CBRA (1998). Os resultados deste trabalho diferem, no entanto, dos encontrados por Fonseca et al. (1996) e Pineda et al. (2000) para animais da mesma raça.

Os testículos dos animais de 35 - 36 meses apresentaram padrões normais, com consistência tenso elástica e perímetro escrotal de $34,7 \pm 1,8 \mathrm{~cm}$, considerados muito bons para a raça Nelore (Fonseca et al., 1997b). Os valores verificados são superiores aos $32,9 \mathrm{~cm}$ encontrados por Maciel et al. (1987), citados por Vale Filho (1997), para touros Nelore aos 36 meses de idade.

Considerando os dados obtidos para características físicas e morfológicas do sêmen, os touros foram classificados como aptos à reprodução, pois se mantiveram no padrão recomendado pelo CBRA (1998) (Tabela 4), à exceção de dois touros (7 e 8), que apresentaram características físicas inadequadas e dados de morfologia não analisados (foram perdidos os dados de morfologia), mas foram mantidos no experimento para estudo da libido e tiveram escore de 2 e 8 , respectivamente (Tabela 5), no teste da libido em curral com período de 10 minutos. No teste a campo, esses touros realizaram 0 e 2 serviços completos, respectivamente, na observação por 13 horas e, ao final da estação, proporcionaram índices de 60,61 e 84,80\% de prenhez, respectivamente, indicando que o comportamento sexual não influenciou as características morfológicas do sêmen do animal 8. Os resultados dos aspectos morfológicos do touro 5 se enquadraram nas normas do CBRA (1998), mas este touro possibilitou taxa de gestação similar à do touro 7 (64,71 e 60,61\%, respectivamente; Tabela 5), do qual não foram analisadas as características morfológicas do sêmen, pois esses touros foram considerados questionáveis no teste da libido feito em curral (escores 3 e 2 , respectivamente) (Tabela 5).

As correlações simples da libido com o peso corporal $(0,12)$, a circunferência escrotal $(-0,04)$, as características físicas e morfológicas do sêmen (turbilhonamento, 0,10; motilidade, 0,13; vigor, 0,10; defeitos maiores, -0,44; defeitos menores, $-0,23$; e defeitos totais, $-0,42$ ) foram próximas de 
Tabela 4 - Biometria testicular e ponderal e características físicas e morfológicas do sêmen de touros Nelore Table 4 - Testicular and weight biometry, physical and morphologic characteristics of the semen of Nelore bulls

\begin{tabular}{|c|c|c|c|c|c|c|c|c|c|c|}
\hline $\begin{array}{l}\text { Touro } \\
\text { Bull }\end{array}$ & $\begin{array}{c}\text { Idade }^{1} \\
\text { Age }\end{array}$ & $\begin{array}{l}\text { Peso }^{2} \\
\text { Weight }\end{array}$ & $\mathrm{CE}^{3}$ & V & $\mathrm{T}$ & MOT & $\begin{array}{l}\text { Vigor } \\
\text { Vigour }\end{array}$ & $\mathrm{DMa}$ & $\mathrm{DMe}$ & TDef \\
\hline 1 & 35 & 537 & 32,5 & 8,0 & 5,0 & 70 & 4,0 & 8,0 & 3,5 & 11,5 \\
\hline 2 & 36 & 576 & 35,5 & 7,0 & 4,0 & 75 & 4,5 & 17,0 & 3,5 & 20,5 \\
\hline 3 & 35 & 528 & 31,5 & 5 & 4,5 & 90 & 4,5 & 6,5 & 6,5 & 13,0 \\
\hline 4 & 36 & 543 & 32,0 & 2,0 & 3,0 & 65 & 3,5 & 10,5 & 3,0 & 13,5 \\
\hline 5 & 35 & 567 & 35,5 & 2,5 & 4,0 & 80 & 4,0 & 6,0 & 3,0 & 9,0 \\
\hline 6 & 36 & 590 & 38,0 & 2,0 & 5,0 & 80 & 4,0 & 14,5 & 1,0 & 15,5 \\
\hline 7 & 35 & 570 & 35,0 & 2,5 & 2,0 & 60 & 2,5 & - & - & - \\
\hline 8 & 38 & 618 & 36,0 & 5,0 & 3,0 & 70 & 3,5 & - & - & - \\
\hline 9 & 34 & 596 & 34,0 & 4,0 & 2,5 & 80 & 4,0 & 6,0 & 2,5 & 8,5 \\
\hline 10 & 35 & 538 & 34,0 & 10,0 & 3,5 & 70 & 3,5 & 3,0 & 5,0 & 8,0 \\
\hline 11 & 36 & 613 & 36,0 & 2,0 & 4,5 & 85 & 4,5 & 8,5 & 3,0 & 11,5 \\
\hline 12 & 35 & 547 & 35,5 & 2,5 & 4,0 & 80 & 4,5 & 26,0 & 8,5 & 34,5 \\
\hline 13 & 35 & 546 & 35,5 & 16,0 & 2,0 & 65 & 3,0 & 12,0 & 17,0 & 29,0 \\
\hline Média & 35,5 & 566,8 & 34,7 & 5,3 & 3,5 & 73,3 & 3,8 & 9,8 & 4,7 & 14,5 \\
\hline Mean & & & & & & & & & & \\
\hline
\end{tabular}

1 em meses, ${ }^{2}$ em kg, ${ }^{3}$ em cm, CE - circunferência escrotal; V - volume do ejaculado (mL); T - turbilhonamento (0 - 5); Mot - motilidade (\%); Dma - defeitos maiores (\%); Dme - defeitos menores (\%); TDef - total dos defeitos (\%).

1 in months, ${ }^{2}$ in kg, ${ }^{3}$ in cm, CE - scrotal circumference; $V$-volume of the ejaculated (mL); T-Mass movement (0 - 5); Mot-spermatic motility (\%); Dma - major defects (\%); Dme - minor defects (\%); TDef-total defects (\%).

Tabela 5 - Classificação de touros Nelore conforme escores obtidos pelo teste da libido em curral, segundo o CBRA (1998), com suas respectivas taxas de prenhez, na estação de monta de 99/00

Table 5 - Classification of Nelore bulls submitted to the libido test in corral scored according to CBRA (1998) and respective pregnancy rates, in the breeding season of $99 / 00$

\begin{tabular}{|c|c|c|c|c|c|c|c|c|c|}
\hline \multirow[b]{2}{*}{$\begin{array}{l}\text { Touro } \\
\text { Bull }\end{array}$} & \multicolumn{8}{|c|}{$\begin{array}{c}\text { Tempo (minutos) } \\
\text { Time (minutes) }\end{array}$} & \multirow[b]{2}{*}{$\begin{array}{c}\text { Prenhez } 99 / 00(\%) \\
\text { Pregnancy }\end{array}$} \\
\hline & $(0-10)$ & $(0-15)$ & $(0-20)$ & $(0-25)$ & $(0-30)$ & $(0-60)$ & $(0-120)$ & $(0-180)$ & \\
\hline 1 & 4 & 9 & 9 & 9 & 9 & 10 & 10 & 10 & 77,8 \\
\hline 2 & 2 & 2 & 2 & 2 & 2 & 2 & 3 & 4 & 63,6 \\
\hline 3 & 2 & 2 & 2 & 2 & 3 & 3 & 10 & 10 & 77,5 \\
\hline 4 & 3 & 3 & 3 & 5 & 5 & 7 & 10 & 10 & 72,7 \\
\hline 5 & 3 & 3 & 3 & 3 & 3 & 3 & 3 & 3 & 64,7 \\
\hline 6 & 2 & 2 & 2 & 3 & 3 & 3 & 4 & 9 & 96,5 \\
\hline 7 & 2 & 3 & 3 & 3 & 3 & 3 & 3 & 3 & 60,6 \\
\hline 8 & 8 & 8 & 8 & 9 & 9 & 9 & 10 & 10 & 84,8 \\
\hline 9 & 3 & 3 & 3 & 3 & 7 & 9 & 10 & 10 & 86,7 \\
\hline 10 & 7 & 8 & 8 & 8 & 8 & 9 & 10 & 10 & - \\
\hline 11 & 2 & 2 & 2 & 2 & 2 & 7 & 10 & 10 & - \\
\hline 12 & 3 & 3 & 7 & 9 & 10 & 10 & 10 & 10 & - \\
\hline 13 & 2 & 4 & 4 & 4 & 9 & 10 & 10 & 10 & - \\
\hline
\end{tabular}

zero ou negativas e confirmam os resultados obtidos por Barbosa (1987) em touros das raças Nelore e Canchim. Corroboram ainda as correlações descritas por Fonseca et al. (1996), Pineda et al. (1997a), Galvani (1998), Santos (2000), Pineda et al. (2000) e Salvador et al. (2003) em touros Nelore, indicando que a conduta sexual do macho não é influenciada pelos aspectos físicos e morfológicos do sêmen, pela circunferência escrotal e pelo peso e, portanto, essas características são independentes.

A classificação dos touros segundo os escores obtidos pelo teste da libido em curral e suas respectivas taxas de prenhez podem ser observadas na Tabela 5. Nenhum touro realizou serviço completo nos 10 minutos de teste proposto pela Tabela de Classificação de Libido de Touros Zebuínos, segundo o CBRA (1998).

Em números absolutos, ao comparar a libido dos touros 2, 5 e 7 à dos demais reprodutores avaliados, observou-se que esses animais apresentaram escores baixos ao final dos 180 minutos de teste (4, 3 e 3 , respectivamente) e proporcionaram taxas de gestação mais baixas $(63,6 ; 64,7$ e $60,6 \%$, respectivamente), coincidindo com os escores mais baixos obtidos no teste da libido por 3 horas.

Verificou-se ainda que, com o aumento de tempo do teste da libido, a maioria dos escores de classificação dos 
reprodutores aumentou, fato observado também por Santos et al. (2004), que, em estudo com touros da raça Nelore, constataram que o aumento de 10 para 15 minutos no tempo do teste aumentou as porcentagens de touros muito bons (de 21,4 para 42,8\%) e excelentes (de 3,6 para 5,4\%) e reduziu o percentual de touros de libido boa (de 42,9 para 25,0\%) ou questionável (de 32,1 para 26,8\%).

Neste estudo, o aumento do tempo do teste de 10 para 15 minutos elevou em $25 \%$ o número de animais aprovados e o de animais bons, que passaram de muito bons a excelentes (Tabela 6), indicando que o tempo de 10 minutos utilizado no teste da libido pode comprometer os resultados de desempenho sexual de touros Nelore. Aos 30 minutos de teste, no entanto, 30,8\% dos animais classificados como questionáveis foram aprovados, com mesma resposta obtida com os touros muito bons e excelentes. Considerando os valores obtidos nos períodos mais longos do teste em curral, verificou-se grande diferença na classificação dos touros: dos dez touros questionáveis $(76,9 \%)$ nos primeiros 10 minutos (Tabela 5) apenas dois animais $(15,4 \%)$ mantiveram-se como questionáveis, embora tenham ganhado um escore no final do período de teste (3 horas).
Considerando o ganho em animais classificados como excelentes, a diferença foi muito satisfatória. Inicialmente, nenhum animal foi classificado como excelente e, ao final, $76,9 \%$ (dez touros) obtiveram escore 10 , sendo classificados como excelentes ou superiores.

No teste da libido realizado a campo (Tabela 7), assim como no teste realizado em curral, os touros também necessitaram de tempo superior ao preconizado pelo CBRA (1998) para identificar as fêmeas em estro, observando-se que nenhum efetuou serviço completo nas duas primeiras horas do teste (das 6 às 8h). À medida que o tempo de teste transcorreu, houve aumento na porcentagem de touros excelentes e redução na de touros questionáveis, evidenciando o melhor comportamento sexual dos animais. $\mathrm{Na}$ primeira hora de teste, dois $(77,8 \%)$ touros foram classificados como questionáveis e dois $(22,2 \%)$, como bons, enquanto, na metade do teste (7 horas), foram detectados dois questionáveis $(22,2 \%)$, três bons $(33,3 \%)$ e quatro excelentes $(44,4 \%)$. No final do teste (13 horas), no entanto, foram observados $11,1 \%$ de touros questionáveis (1), 22,2\% bons (2), 11,1\% muito bons (1) e 55,6\% excelentes (5), ou seja, $89,9 \%$ de animais aptos quanto à libido (8) (Tabela 7).

Tabela 6 - Classificação de touros Nelore segundo escores obtidos pelo teste da libido em curral, conforme o CBRA (1998) Table 6 - Classification of Nelore bulls (\%) submitted to the libido test in corral scored according to CBRA (1998)

\begin{tabular}{|c|c|c|c|c|c|c|c|c|}
\hline \multirow[b]{2}{*}{$\begin{array}{l}\text { Classificação } \\
\text { Classification }\end{array}$} & \multicolumn{8}{|c|}{$\begin{array}{c}\text { Tempo (Minutos) } \\
\text { Time (minutes) }\end{array}$} \\
\hline & $(0-10)$ & $(0-15)$ & $(0-20)$ & $(0-25)$ & $(0-30)$ & $(0-60)$ & $(0-120)$ & $(0-180)$ \\
\hline Questionável (Dubious) $(0-3)$ & 76,9 & 69,2 & 61,5 & 53,8 & 46,1 & 38,5 & 23,1 & 15,4 \\
\hline Bom (Good) $(4-6)$ & 7,7 & 7,7 & 7,7 & 15,4 & 7,7 & 0,00 & 7,7 & 7,7 \\
\hline Muito bom (Very good) $(7-8)$ & 15,4 & 15,4 & 23,1 & 7,7 & 15,4 & 15,4 & 0,00 & 0,00 \\
\hline Excelente (Excellent) $(9-10)$ & 0,00 & 7,7 & 7,7 & 23,1 & 30,8 & 46,1 & 69,2 & 76,9 \\
\hline
\end{tabular}

Tabela 7 - Classificação de touros Nelore segundo escores obtidos pelo teste da libido a campo, conforme o CBRA (1998), com suas respectivas taxas de prenhez, na estação de monta de 99/00

Table 7 - Classification of sexual behavior of Nelore bulls submitted to evaluation at field, scored according to CBRA (1998), and respective pregnancy rates in the breeding season of $99 / 00$

\begin{tabular}{|c|c|c|c|c|c|c|c|c|c|c|c|c|c|c|}
\hline \multirow[b]{2}{*}{$\begin{array}{l}\text { Touro } \\
\text { Bull }\end{array}$} & \multicolumn{13}{|c|}{$\begin{array}{c}\text { Tempo (em horas) } \\
\text { Time (hours) }\end{array}$} & \multirow[b]{2}{*}{$\begin{array}{c}\text { Prenhez } 99 / 00(\%) \\
\text { Pregnancy }\end{array}$} \\
\hline & 1 & 2 & 3 & 4 & 5 & 6 & 7 & 8 & 9 & 10 & 11 & 12 & 13 & \\
\hline 1 & 4 & 4 & 4 & 4 & 4 & 4 & 4 & 4 & 4 & 4 & 4 & 4 & 4 & 77,8 \\
\hline 2 & 3 & 3 & 3 & 3 & 3 & 3 & 3 & 3 & 3 & 3 & 3 & 3 & 3 & 63,6 \\
\hline 3 & 1 & 3 & 3 & 3 & 3 & 3 & 3 & 5 & 9 & 10 & 10 & 10 & 10 & 77,5 \\
\hline 4 & 3 & 3 & 3 & 3 & 4 & 4 & 5 & 5 & 5 & 5 & 5 & 5 & 5 & 72,7 \\
\hline 5 & 3 & 7 & 8 & 9 & 9 & 9 & 9 & 9 & 9 & 9 & 9 & 9 & 9 & 64,7 \\
\hline 6 & 3 & 3 & 3 & 3 & 3 & 5 & 9 & 9 & 9 & 9 & 9 & 9 & 9 & 96,5 \\
\hline 7 & 2 & 2 & 2 & 2 & 2 & 3 & 4 & 7 & 7 & 7 & 7 & 7 & 7 & 60,6 \\
\hline 8 & 4 & 4 & 9 & 9 & 9 & 9 & 9 & 10 & 10 & 10 & 10 & 10 & 10 & 84,8 \\
\hline 9 & 3 & 4 & 8 & 9 & 9 & 9 & 9 & 9 & 9 & 10 & 10 & 10 & 10 & 86,7 \\
\hline
\end{tabular}


O teste da libido proposto para a avaliação a campo por 13 horas (das 6 às 19h) não viabilizou a observação do comportamento sexual durante o período noturno.

Dessa forma, o tempo de 10 minutos de avaliação da libido em curral realizado por Fonseca et al. (1997a), Pineda (1997a , b), Galvani (1998) e Costa e Silva et al. (1999) não foi adequado aos animais, pois não foi suficiente para que os reprodutores expressassem seu potencial sexual. Conseqüentemente, novos estudos devem ser realizados para elucidar o melhor ambiente para o teste da libido em animais zebuínos; devem ser avaliados testes em piquetes afastados do curral, sem fêmeas amarradas ou contidas em troncos, de modo que a interferência no comportamento sexual dos touros possa ser minimizada. O tempo de 30 minutos foi mais eficiente para testar os touros da raça Nelore, fato comprovado pela análise de regressão quadrática, pela qual dos 13 animais testados, sete obtiveram escores iguais ou superiores a $5(53,8 \%)$, sendo considerados bons, muito bons ou excelentes. A análise do tempo de 120 minutos comprovou tendência de os animais atingirem um patamar máximo no qual seus escores tendem a 10.

Na Tabela 8 constam as taxas de prenhez no primeiro ciclo da estação de monta (21 dias). O touro 9 proporcionou a maior taxa de gestação $(60,0 \%)$, embora, pelo teste de $\chi^{2}$, não tenha diferenciado dos touros $8(51,5 \%)$ e $3(42,5 \%)$, que não diferiram do animal $6(37,9 \%)$. A análise dos touros que resultaram em menor taxa de gestação ( 7 - 9,1\%; 5 - 17,6\%; 4 - 21,2\%; 2 - 27,3\%) não comprovou diferença ( $P>0,05)$. Os touros 9 e 3, com baixa libido, possibilitaram taxas de gestação bem próximas $(\mathrm{P}>0,05)$ da obtida no touro 8 , com a libido muito boa. A diferença na taxa de gestação entre os lotes de fêmeas provavelmente esteve relacionada ao baixo peso corporal das fêmeas de alguns grupos que se encontravam na fase pré-puberal ou puberal.
A média geral da taxa de gestação $(32,2 \%)$ proporcionada pelos touros nos primeiros 21 dias da estação (primeiro ciclo) foi inferior aos valores obtidos por Fonseca et al. (1996), Galvani (1998) e Pineda et al. (2000), em estudo com touros de alta libido $(6,4 ; 60,6$ e $62,5 \%$, respectivamente) Todavia, o touro 9 , que promoveu $60,0 \%$ de prenhez (resultado semelhante aos encontrados por esses autores), teve escore 3 (questionável) no teste da libido.

Neste estudo os touros foram separados por um período de dez dias após o primeiro ciclo, sendo submetidos ao exame ultra-sonográfico 43 dias após o início da estação. O diagnóstico de gestação mais precoce foi aos 22 dias de gestação, enquanto os diagnósticos posteriores foram realizados aos 54 e 75 dias (segundo e terceiro ciclo). As taxas de gestação no primeiro (21dias) e segundo ciclos (42 dias) foram baixas, provavelmente porque algumas fêmeas não haviam alcançado a puberdade ou maturidade sexual no primeiro ciclo. A não-realização de exames ginecológicos nas fêmeas no início da estação de monta, em decorrência do manejo adotado pela empresa, comprometeu as taxas de gestação do lote nos dois primeiros ciclos. Provavelmente, algumas fêmeas não se encontravam púberes no início da estação de monta, mas atingiram a puberdade no decorrer da estação de monta, embora o grupo de animais fosse homogêneo à condição corporal. A partir do segundo ciclo (42 dias), no entanto, constatou-se, por meio de imagens ultrasonográficas, crescimento folicular e presença de corpo lúteo, evidenciando a presença de atividade ovariana nas fêmeas gestantes.

$\mathrm{Na}$ Tabela 9 são descritas as taxas de prenhez no segundo ciclo da estação de monta. O touro 6 proporcionou taxa de gestação mais alta $(86,2 \%)$ no ciclo de 42 dias e não diferiu do touro $9(73,3 \%)$. Os touros 8 e 9 não diferiram entre si, mas diferiram dos touros $1(44,4 \%), 2(33,3 \%), 3(55,0 \%)$,

Tabela 8 - Taxa de prenhez em rebanho Nelore submetido à proporção média touro:vaca de 1:33 em estação de monta de 21 dias Table 8 - Pregnancy rate of Nelore bulls submitted to evaluation at field using a bull:cow proportion equal to 1:33 during a breeding season of 21 days

\begin{tabular}{|c|c|c|c|c|c|c|c|c|c|c|c|}
\hline \multirow{2}{*}{$\begin{array}{l}\text { Touro } \\
\text { Bull }\end{array}$} & \multirow{2}{*}{$\begin{array}{c}\text { Gestante }(\%) \\
\text { Pregnant }\end{array}$} & \multicolumn{10}{|c|}{$\begin{array}{c}10 \text { ciclo }(21 \text { dias }) \\
1^{\text {st }} \text { cycle }(21 \text { days })\end{array}$} \\
\hline & & No pregnant & Total & & & & & & & & \\
\hline 1 & $6(22,2)$ & $21 \quad(77,8)$ & 27 & $\mathrm{a}$ & & & & & & & \\
\hline 2 & $9(27,3)$ & $24(72,7)$ & 33 & a & $\mathrm{c}$ & & & & & & \\
\hline 3 & $17(42,5)$ & $23(57,5)$ & 40 & $\mathrm{a}$ & $\mathrm{c}$ & $\mathrm{e}$ & & & & & \\
\hline 4 & $7(21,2)$ & $26(78,8)$ & 33 & $\mathrm{a}$ & $\mathrm{c}$ & $\mathrm{e}$ & $\mathrm{g}$ & & & & \\
\hline 5 & $6(17,6)$ & $28(82,3)$ & 34 & $\mathrm{a}$ & $\mathrm{c}$ & $\mathrm{f}$ & $\mathrm{g}$ & $\mathrm{i}$ & & & \\
\hline 6 & $11(37,9)$ & $18(62,1)$ & 29 & $\mathrm{a}$ & $\mathrm{c}$ & $\mathrm{e}$ & $\mathrm{g}$ & $\mathrm{i}$ & $\mathrm{k}$ & & \\
\hline 7 & $3(9,1)$ & $30(90,9)$ & 33 & $\mathrm{a}$ & $\mathrm{c}$ & $\mathrm{f}$ & $\mathrm{g}$ & $\mathrm{i}$ & 1 & $\mathrm{~m}$ & \\
\hline 8 & $17(51,5)$ & $16(48,5)$ & 33 & $\mathrm{~b}$ & d & $\mathrm{e}$ & $\mathrm{h}$ & $\mathrm{j}$ & $\mathrm{k}$ & $\mathrm{n}$ & o \\
\hline 9 & $18(60,0)$ & $12(40,0)$ & 30 & $\mathrm{~b}$ & $\mathrm{~d}$ & $\mathrm{e}$ & $\mathrm{h}$ & $\mathrm{j}$ & 1 & $\mathrm{n}$ & o \\
\hline Total & $94(32,2)$ & $198(67,8)$ & 292 & & & & & & & & \\
\hline
\end{tabular}

$\chi^{2}$ (Análise de qui-quadrado) $=3,84\left(\mathrm{Gl}_{1} ; \mathrm{P}<0,05\right)$. 
$4(33,3 \%), 5(29,4 \%)$ e $7(30,3 \%)(\mathrm{P}<0,05)$. Por outro lado, os touros que apresentaram desempenhos inferiores $(2,4,5$ e 7$)$ na taxa de gestação no segundo ciclo não diferiram entre si (P>0,05). Ressalta-se que, com o touro 6 (escore 2), obteve-se taxa de gestação superior à encontrada com o touro 8 (muito boa libido) e que não diferiu do touro 9 (baixa libido) na fase inicial do teste de curral e a campo (Tabelas 5 e 7).

No segundo ciclo,o desempenho na média de prenhez $(49,3 \%)$ foi mais baixo que os descritos por Fonseca et al. (1996), Galvani (1998) e Pineda et al. (2000) em touros de alta libido (72,5; 79,2; e 72,5\% respectivamente). O desempenho do touro 9 foi superior ao dos animais utilizados por Fonseca et al. (1996) e Pineda et al. (2000) e inferior ao dos animais estudados por Galvani (1998). Contudo, a média do touro 6 foi superior $(86,2 \%)$ à encontrada nos mesmos experimentos. Os reprodutores 9 e 6 apresentaram, respectivamente, escores 3 e 2 no teste da libido (questionáveis), o que sugere falha na metodologia do teste proposto pelo CBRA (1998) e comprova a necessidade de outros estudos.

Analisando a taxa de gestação no terceiro ciclo de estação de monta (63 dias) (Tabela 10), observa-se que o touro 6 resultou em maior taxa de gestação $(96,5 \%)$, não diferindo do $8(81,8 \%)$ e do $9(83,3 \%)(\mathrm{P}>0,05)$. Os reprodutores que tiveram desempenhos inferiores $(2,5$ e 7$)$ não diferiram entre si $(\mathrm{P}>0,05)$. A campo, os touros de baixa e média libido no curral não diferiram quanto à taxa de gestação, o que também foi observado no primeiro e segundo ciclos da estação de monta.

No terceiro ciclo da estação de monta, observou-se o mesmo comportamento dos ciclos anteriores quanto à taxa de prenhez. Touros de baixa libido (6 e 9) resultaram em médias aproximadas ou maiores (83,3 e 96,5\%) (Tabela 10) que as obtidas com animais de muito boa libido (8) e com alta libido analisados por Fonseca et al. (1996), Galvani (1998)

Tabela 9 - Taxa de prenhez em rebanho Nelore submetido à proporção média touro:vaca de 1:33 em período de 42 dias de estação de monta

Table 9 - Pregnancy rate of Nelore bulls submitted to evaluation at field using a bull:cow proportion equal to 1:33 during a breeding season of 42 days

\begin{tabular}{|c|c|c|c|c|c|c|c|c|c|c|c|}
\hline \multirow[b]{2}{*}{$\begin{array}{l}\text { Touro } \\
\text { Bull }\end{array}$} & \multirow[b]{2}{*}{$\begin{array}{c}\text { Gestante }(\%) \\
\text { Pregnancy }\end{array}$} & \multicolumn{10}{|c|}{$\begin{array}{l}2^{\mathrm{o}} \text { ciclo (42 dias) } \\
\left.2^{\text {nd }} \text { cycle (42 days }\right)\end{array}$} \\
\hline & & $\begin{array}{c}\text { Não-gestante }(\%) \\
\text { No pregnant }\end{array}$ & $\begin{array}{c}\text { Total } \\
\text { Total }\end{array}$ & & & & & $\chi^{2}$ & & & \\
\hline 1 & $12(44,4)$ & $15(55,6)$ & 27 & $\mathrm{a}$ & & & & & & & \\
\hline 2 & $11(33,3)$ & $22(66,7)$ & 33 & $\mathrm{a}$ & $\mathrm{c}$ & & & & & & \\
\hline 3 & $22(55,0)$ & $18(45,0)$ & 40 & $\mathrm{a}$ & $\mathrm{c}$ & $\mathrm{e}$ & & & & & \\
\hline 4 & $11(33,3)$ & $22(66,7)$ & 33 & $\mathrm{a}$ & $\mathrm{c}$ & $\mathrm{e}$ & $\mathrm{g}$ & & & & \\
\hline 5 & $10(29,4)$ & $24(70,6)$ & 34 & $\mathrm{a}$ & $\mathrm{c}$ & $\mathrm{f}$ & $\mathrm{g}$ & $\mathrm{i}$ & & & \\
\hline 6 & $25(86,2)$ & $4(13,8)$ & 29 & $\mathrm{~b}$ & $\mathrm{~d}$ & $\mathrm{f}$ & $\mathrm{h}$ & $\mathrm{j}$ & $\mathrm{k}$ & & \\
\hline 7 & $10(30,3)$ & $23(69,7)$ & 33 & $\mathrm{a}$ & $\mathrm{c}$ & $\mathrm{f}$ & $\mathrm{g}$ & $\mathrm{i}$ & 1 & $\mathrm{~m}$ & \\
\hline 8 & $21 \quad(63,6)$ & $12(36,4)$ & 33 & $\mathrm{a}$ & $\mathrm{d}$ & $\mathrm{e}$ & $\mathrm{h}$ & $\mathrm{j}$ & 1 & $\mathrm{n}$ & o \\
\hline 9 & $22(73,3)$ & $8(26,7)$ & 30 & $\mathrm{~b}$ & $\mathrm{~d}$ & $\mathrm{E}$ & $\mathrm{h}$ & $\mathrm{j}$ & $\mathrm{k}$ & $\mathrm{n}$ & o \\
\hline Total & $144(49,3)$ & $148(50,7)$ & 292 & & & & & & & & \\
\hline
\end{tabular}

$\chi^{2}$ (Análise de qui-quadrado) $=3,84\left(\mathrm{Gl}_{1} ; \mathrm{P}<0,05\right)$.

Tabela 10 - Taxa de prenhez em rebanho Nelore submetido à proporção média touro:vaca de 1:33 durante 63 dias de estação de monta Table 10 - Pregnancy of Nelore bulls submitted to evaluation at field using a bull:cow proportion equal to 1:33 during a breeding season of 63 days

\begin{tabular}{|c|c|c|c|c|c|c|c|c|c|c|c|}
\hline \multirow{3}{*}{$\begin{array}{l}\text { Touro } \\
\text { Bull }\end{array}$} & \multirow{3}{*}{$\begin{array}{c}\text { Gestante }(\%) \\
\text { Pregnancy }\end{array}$} & \multicolumn{10}{|c|}{$\begin{array}{l}30 \text { ciclo (42 dias) } \\
\left.3^{\text {rd }} \text { cycle ( } 63 \text { days }\right)\end{array}$} \\
\hline & & Não-gestante (\%) & Total & & & & & $\chi^{2}$ & & & \\
\hline & & No pregnant & Total & & & & & & & & \\
\hline 1 & $19(70,4)$ & $8(29,6)$ & 27 & $\mathrm{a}$ & & & & & & & \\
\hline 2 & $18(54,5)$ & $15(45,5)$ & 33 & $\mathrm{a}$ & $\mathrm{c}$ & & & & & & \\
\hline 3 & $31(77,5)$ & $9(22,5)$ & 40 & $\mathrm{a}$ & $\mathrm{c}$ & $\mathrm{e}$ & & & & & \\
\hline 4 & $23(69,7)$ & $10(30,3)$ & 33 & $\mathrm{a}$ & $\mathrm{c}$ & $\mathrm{e}$ & $\mathrm{g}$ & & & & \\
\hline 5 & $16(47,0)$ & $18(52,9)$ & 34 & $\mathrm{a}$ & $\mathrm{c}$ & $\mathrm{f}$ & $\mathrm{g}$ & $\mathrm{i}$ & & & \\
\hline 6 & $28(96,5)$ & $1(3,4)$ & 29 & $\mathrm{~b}$ & $\mathrm{~d}$ & $\mathrm{f}$ & $\mathrm{h}$ & $\mathrm{j}$ & $\mathrm{k}$ & & \\
\hline 7 & $19(57,6)$ & $14(42,4)$ & 33 & $\mathrm{a}$ & $\mathrm{c}$ & $\mathrm{e}$ & $\mathrm{g}$ & $\mathrm{i}$ & 1 & $\mathrm{~m}$ & \\
\hline 8 & $27(81,8)$ & $6(18,2)$ & 33 & $\mathrm{a}$ & $\mathrm{d}$ & $\mathrm{e}$ & $\mathrm{g}$ & $\mathrm{j}$ & $\mathrm{k}$ & $\mathrm{m}$ & $\mathrm{n}$ \\
\hline 9 & $25(83,3)$ & $5(16,7)$ & 30 & $\mathrm{a}$ & $\mathrm{d}$ & $\mathrm{e}$ & $\mathrm{g}$ & $\mathrm{j}$ & $\mathrm{k}$ & $\mathrm{m}$ & $\mathrm{n}$ \\
\hline Total & $206(70,5)$ & $86(29,4)$ & 292 & & & & & & & & \\
\hline
\end{tabular}


e Pineda et al. (2000), de 88,8; 90,9 e 88,8\% de prenhez, respectivamente, ao final de 63 dias (terceiro ciclo) de estação de monta.

Ao final da estação de monta de 120 dias, os animais não apresentaram bom desempenho quanto à taxa de prenhez $(75,7 \%)$ (Tabela 11). Entretanto, o touro 6 (escores 9 e 9 para os teste de libido no curral e a campo, respectivamente) foi superior aos demais, com índice de $96,5 \%$ de prenhez (considerado excelente), à exceção dos reprodutores 8 e 9 , que também proporcionaram bons índices $(84,8$ e $86,7 \%)$. Os touros 2,5 e 7 ocasionaram a redução da taxa de gestação, pois apresentaram valores de
63,$6 ; 64,7$ e 60,6\%, respectivamente, resultando em escores baixos ao final dos 180 minutos de teste do curral (4, 3 e 3 , respectivamente) e escores de 3, 9 e 7, respectivamente, para o teste a campo.

Ressalta-se que, nos três ciclos e ao final da estação de monta de 120 dias, não houve diferença $(\mathrm{P}>0,05)$ entre os diagnósticos de gestação proporcionados aos lotes de novilhas por touros de baixa libido (6 e 9) e de libido muito boa (8), comprovando que este teste deveria ser reformulado na tentativa de detectar estes animais que não manifestaram todo seu comportamento sexual no curral.

Tabela 11 - Taxa de prenhez em rebanho Nelore submetido à proporção média touro:vaca de 1:33 em estação de monta de 120 dias Table 11 - Pregnancy of Nelore bulls submitted to evaluation at field using a bull:cow proportion equal to 1:33 during a breeding season of 120 days

\begin{tabular}{|c|c|c|c|c|c|c|c|c|c|c|c|}
\hline \multirow[b]{2}{*}{$\begin{array}{l}\text { Touro } \\
\text { Bull }\end{array}$} & \multirow[b]{2}{*}{$\begin{array}{c}\text { Gestante }(\%) \\
\text { Pregnancy }\end{array}$} & \multicolumn{10}{|c|}{$\begin{array}{l}\text { Final da estação de monta (120 dias) } \\
\text { End of breeding season (120 days) }\end{array}$} \\
\hline & & $\begin{array}{c}\text { Não-gestante }(\%) \\
\text { No pregnant }\end{array}$ & $\begin{array}{l}\text { Total } \\
\text { Total }\end{array}$ & & & & & $\chi^{2}$ & & & \\
\hline 1 & $21(77,8)$ & $6(22,2)$ & 27 & $\mathrm{a}$ & & & & & & & \\
\hline 2 & $21(63,6)$ & $12(36,4)$ & 33 & $\mathrm{a}$ & $\mathrm{c}$ & & & & & & \\
\hline 3 & $31(77,5)$ & $9(22,5)$ & 40 & $\mathrm{a}$ & $\mathrm{c}$ & $\mathrm{e}$ & & & & & \\
\hline 4 & $24(72,7)$ & $9(27,3)$ & 33 & $\mathrm{a}$ & $\mathrm{c}$ & $\mathrm{e}$ & $\mathrm{g}$ & & & & \\
\hline 5 & $22(64,7)$ & $12(35,3)$ & 34 & $\mathrm{a}$ & $\mathrm{c}$ & $\mathrm{e}$ & $\mathrm{g}$ & $\mathrm{i}$ & & & \\
\hline 6 & $28(96,5)$ & $1(3,4)$ & 29 & $\mathrm{~b}$ & $\mathrm{~d}$ & $\mathrm{f}$ & $\mathrm{h}$ & $\mathrm{j}$ & $\mathrm{k}$ & & \\
\hline 7 & $20(60,6)$ & $13(39,4)$ & 33 & $\mathrm{a}$ & $\mathrm{c}$ & $\mathrm{e}$ & $\mathrm{g}$ & $\mathrm{i}$ & 1 & $\mathrm{~m}$ & \\
\hline 8 & $28(84,8)$ & $5(15,1)$ & 33 & $\mathrm{a}$ & $\mathrm{d}$ & $\mathrm{e}$ & $\mathrm{g}$ & $\mathrm{i}$ & $\mathrm{k}$ & $\mathrm{n}$ & o \\
\hline 9 & $26(86,7)$ & $4(13,3)$ & 30 & $\mathrm{a}$ & $\mathrm{d}$ & $\mathrm{e}$ & $\mathrm{g}$ & $\mathrm{j}$ & $\mathrm{k}$ & $\mathrm{n}$ & o \\
\hline Total & $221(75,7)$ & $71(24,3)$ & 292 & & & & & & & & \\
\hline
\end{tabular}

$\chi^{2}$ (Análise de qui-quadrado) $=3,84\left(\mathrm{Gl}_{1} ; \mathrm{P}<0,05\right)$.

\section{Conclusões}

Em números absolutos, touros Nelore foram diferentes no campo e no curral quanto ao reconhecimento da fêmea em estro, à receptividade da fêmea e ao acasalamento. Não foi observada relação das medidas testiculares e ponderais e das características seminais com a libido dos touros, indicando que essas características são independentes.

Os padrões de classificação da libido propostos pelo Colégio Brasileiro de Reprodução Animal (1998) para avaliação em curral subestimam a libido de touros Nelore. $\mathrm{O}$ tempo de observação de 30 minutos foi mais eficiente para o teste da libido em curral em animais Nelore.

O teste da libido realizado a campo no período diurno não foi eficaz em predizer a libido de todos os animais, provavelmente em decorrência do comportamento sexual noturno de alguns reprodutores.

\section{Agradecimento}

À Empresa AMANAH S/A - Fazenda Mundo Novo, Brotas/SP, pela colaboração durante a realização deste trabalho.

\section{Literatura Citada}

ANUALPEC. Anuário estatístico de produção animal. São Paulo: FNP, 2002. 385p.

ASSOCIAÇÃO BRASILEIRA DE INSEMINAÇÃO ARTIFICIAL ASBIA. [2003]. Manual de inseminação artificial. Disponível em: http://www.asbia.org.br/. Acesso em: 11/03/2006.

BARBOSA, R.J. Comportamento sexual, biometria testicular, aspectos do sêmen e níveis plasmáticos de testosterona em touros Canchim e Nelore. Belo Horizonte: Universidade Federal de Minas Gerais, 1987. 132p. Dissertação (Mestrado em Medicina Veterinária) - Universidade Federal de Minas Gerais, 1987.

BLOM, E. The ultrastructure of some characteristic sperm deffects and a proposal for a new classification of the bull spermiogram. Nordisk Veterinarer Medicin, v.25, p.383-391, 1973. 
BLOM, E. Pathological condictions in the genital organs and in the semen of group for rejection of breeding bulls for import or export to and from Denmark, 1958 - 1982. Nordisk Veterinarer Medicin, v.35, n.3, p.105-130, 1983.

COLÉGIO BRASILEITO DE REPRODUÇÃO ANIMAL - CBRA. Manual para exame andrológico e avaliação de sêmen animal. 2.ed. Belo Horizonte: CBRA, 1998. 49p.

CHENOWETH, P.J. Sexual behavior of the bull: a review. Journal Dairy Science, v.66, n.1, p.173-179, 1983.

COSTA e SILVA, E.V. Capacidade reprodutiva de touros Nelore: exame andrológico, teste de comportamento sexual e desafio de fertilidade. Belo Horizonte: Universidade Federal de Minas Gerais, 1994. 102p. Dissertação (Mestrado em Medicina Veterinária) - Universidade Federal de Minas Gerais, 1994.

COSTA e SILVA, E.V.; SERENO, J.R.B.; COSTA, M.J.R. Comportamento sexual de touros nelore (Bos taurus indicus) e Pantaneiro (Bos taurus taurus) durante os procedimentos de teste de libido. Revista Brasileira de Reprodução Animal, v.23, n.3, p.214-216, 1999.

CRUDELI, G.A. Avaliação da aptidão reprodutiva de touros da raça Nelore e efeito sobre a taxa de gestação do rebanho. Belo Horizonte: Universidade Federal de Minas Gerais, 1990. 152p. Dissertação (Mestrado em Medicina Veterinária) Universidade Federal de Minas Gerais, 1990.

FONSECA, V.O.; CRUDELI, G.A.; COSTA e SILVA, E.V. et al. Potencial reprodutivo de touros da raça Nelore (Bos taurus indicus) em monta natural: proporção touro:vaca 1:40 e fertilidade. Revista Brasileira de Reprodução Animal, v.15, p. 103-108, 1991 .

FONSECA, V.O. Avaliação da capacidade reprodutiva de touros Nelore: aspectos andrológicos e comportamentais. Belo Horizonte: Universidade Federal de Minas Gerais, 1995. 37p. Monografia (Graduação em Medicina Veterinária) - Universidade Federal de Minas Gerais, 1995.

FONSECA, V.O.; PINEDA, N.R.; PROENÇA, R.V. Libido, capacidade de serviço e potencial reprodutivo de touros da raça nelore (Bos taurus indicus) em estação de monta curta, utilizando a proporção touro:vaca 1:50 e 1:80. In: CONGRESSO BRASILEIRO DE RAÇAS ZEBUÍNAS, 2., 1996, Uberaba. Anais... Uberaba: Associação Brasileira dos Criadores de gado Zebu, 1996. p.21-22.

FONSECA, V.O.; FRANCO, C.S.; BERGMANN, J.A.G. et al. Potencial reprodutivo de touros da raça Nelore (Bos taurus indicus) acasalados com elevado número de vacas. Arquivo Brasileiro de Medicina Veterinária e Zootecnia, v.49, n.1, p.53-62, 1997a.

FONSECA, V.O.; SANTOS, N.R.; MALINSKI, P.R. Classificação andrológica de touros zebus (Bos taurus indicus) com base no perímetro escrotal e características morfológicas de sêmen. Revista Brasileira de Reprodução Animal, v.21, n.2, p.3639, 1997b

GALVANI, F. Desempenho reprodutivo de touros de alta libido da raça Nelore. Viçosa, MG: Universidade Federal de Viçosa, 1998. 69p. Dissertação (Mestrado em Medicina Veterinária) Universidade Federal de Viçosa, 1998.
INSTITUTO BRASILEIRO DE GEOGRAFIA E ESTATÍSTICA IBGE. [2004]. Pesquisa Pecuária Municipal (PPM) 1990 a 2002, SIDRA - Sistema IBGE de Recuperação Automática: Quantidade de Animais - Unidades. Disponível em: <http:/ /www.ibge.org.br.> Acesso em: 15/04/2005.

PINEDA, N.R.; LEMOS, P.F. Contribuição ao estudo da influência da libido e da capacidade de serviço sobre a taxa de concepção em Nelore. Boletim Indústria Animal, v.51, n.1, p.61-68, 1994.

PINEDA, N.R. Provas de desempenho sexual. Revista Brasileira de Reprodução Animal, v.20, n.3-4, p.112-119, 1996.

PINEDA, N.R.; LEMOS, P.F.; FONSECA, V.O. Comparação entre dois testes de Avaliação do comportamento sexual (libido) de touros Nelore (Bos taurus indicus). Revista Brasileira de Reprodução Animal, v.21, n.4, p.29-34, 1997a.

PINEDA, N.R.; FONSECA, V.O.; PROENÇA, R.V. Potencial reprodutivo de touros de alta libido da raça nelore (Bos taurus indicus). Revista Brasileira de Reprodução Animal, v.21, n.2, p.45-48, 1997b.

PINEDA, N.R.; FONSECA, V.O.; PROENÇA, R.V. Potencial reprodutivo de touros Nelore: libido, capacidade de serviço e eficiência em acasalamentos com elevada proporção de vacas. Revista Brasileira de Reprodução Animal, v.24, n.1, p.4451,2000

SALVADOR, D.F.; ANDRADE, V.J.; VALE FILHO, V.R. et al. Avaliação da libido de touros Nelore adultos em curral e sua associação com características andrológicas e desempenho reprodutivo a campo. Arquivo Brasileiro de Medicina Veterinária e Zootecnia, v.55, n.5, p.588-593, 2003.

SANTOS, N.R.; HENRY, M.; COSTA, M.P. et al. Comportamento sexual de touros nelore (Bos taurus indicus) em pasto frente a fêmeas com cio induzido por prostaglandina F2 $\alpha$. Revista Brasileira de Reprodução Animal, v.23, n.3, p.216-218, 1999.

SANTOS, M.D. Comportamento sexual, qualidade seminal e eficiência reprodutiva de touros da raça Nelore em regime de monta natural. Viçosa, MG: Universidade Federal de Viçosa, 2000. 88p. Tese (Doutorado em Zootecnia) - Universidade Federal de Viçosa, 2000.

SANTOS, M.D.; TORRES, C.A.A.; RUAS, J.R.M. et al. Teste da libido e atividade de monta em touros da raça Nelore. Arquivo Brasileiro de Medicina Veterinária e Zootecnia, v.56, n.4, p.504-510, 2004.

VALE FILHO, V.R. Andrologia no touro: avaliação genital, exame de sêmen e classificação por pontos. Revista Brasileira de Reprodução Animal, v.21, n.3, p.7-13, 1997.

YASSU, F. Teste de capacitação de touros racionaliza o manejo. DBO Rural, n.185, p.16-20, 1996. 